\title{
MicroRNAs serving as potential biomarkers and therapeutic targets in nasopharyngeal carcinoma: a critical review
}

Katherine Ting-Wei Lee ${ }^{1,2}$, MSc.

Juan-King $\operatorname{Tan}^{3}$, MBChB

Alfred King-yin $\mathrm{Lam}^{1} *$, MBBS, MD, PhD, FRCPA.

Sook-Yee $\mathrm{Gan}^{4} * \mathrm{PhD}$

${ }^{1}$ Cancer Molecular Pathology, School of Medicine, Menzies Health Institute Queensland, Griffith University, Gold Coast, Queensland, Australia

${ }^{2}$ School of Postgraduate Studies and Research, International Medical University, Bukit Jalil, 57000 Kuala Lumpur, Malaysia

${ }^{3}$ School of Medicine, International Medical University, Bukit Jalil, 57000 Kuala Lumpur, Malaysia

${ }^{4}$ School of Pharmacy, International Medical University, Bukit Jalil, 57000 Kuala Lumpur, Malaysia

*Co-corresponding authors: Alfred King-yin Lam \& Sook-Yee Gan

a.lam@griffith.edu.au \& sookyee_gan@imu.edu.my,

Running head: microRNAs in nasopharyngeal carcinoma

Address for correspondence:

Professor Alfred Lam

Head of Pathology, Griffith Medical School, Gold Coast Campus, Gold Coast QLD 4222, Australia.

E-mail: a.lam@griffith.edu.au

Telephone +61 756780718

\section{Sook-Yee Gan}

Head of Life Sciences, School of Pharmacy, International Medical University, Bukit Jalil, 57000 Kuala Lumpur, Malaysia

E-mail: sookyee_gan@imu.edu.my

Telephone +60327317518 


\section{Contents}

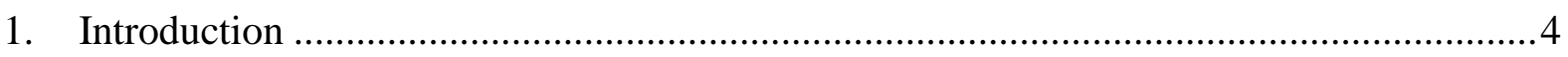

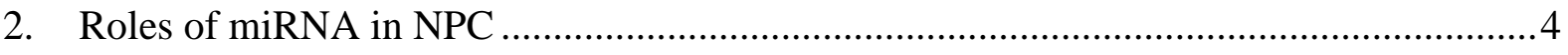

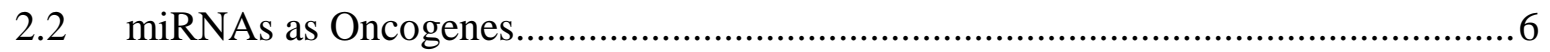

2.3 Roles of miRNA in Cell Cycle Progression ..............................................................

3. miRNA Implicated in EBV Positive NPC...............................................................

3.1 Latent membrane protein 1 .........................................................................

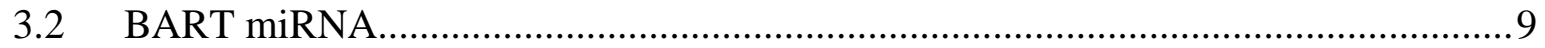

4. Combining miRNA Treatment with Current NPC Treatments ...........................................11

5. miRNA as New Therapeutic Targets in NPC..............................................................12

6. miRNA as diagnostic and prognostic biomarker in NPC................................................12

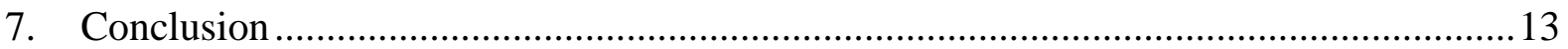

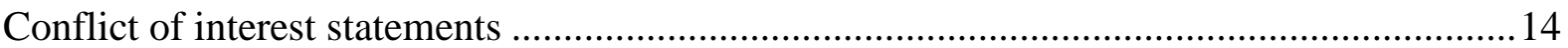

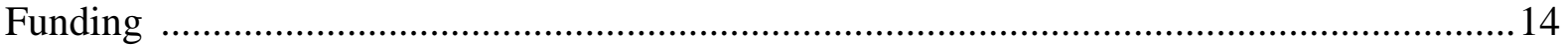

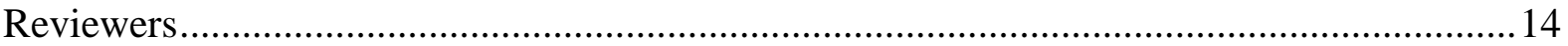

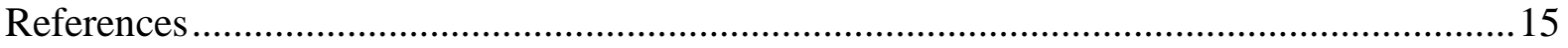

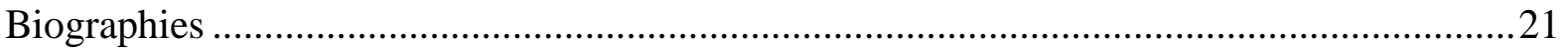




\begin{abstract}
Despite significant medical advancement, nasopharyngeal carcinoma (NPC) remains one of the most difficult cancers to detect and treat where it continues to prevail especially among the Asian population. miRNAs could act as tumour suppressor gene or oncogene in NPC. They played important roles in the pathogenesis of NPC by regulating specific target genes which are involved in various cellular processes and pathways. In particular, studies on miRNAs related to the Epstein Barr virus (EBV)-encoded latent membrane protein one (LMP1) and EBV miRNA- BART miRNA confirmed the link between EBV and NPC. Both miRNA and its target genes could potentially be exploited for prognostic and therapeutic strategies. They are also important in predicting the sensitivity of NPC to radiotherapy and chemotherapy. The detection of stable circulating miRNAs in plasma of NPC patients has raised the potential of miRNAs as novel diagnostic and prognostic markers. To conclude, understanding the roles of miRNA in NPC will identify ways to improve the management of patients with NPC.
\end{abstract}

\title{
Key words
}

MicroRNA; Nasopharyngeal carcinoma; Cancer; Epstein-Barr virus; BART-miRNAs; Biomarkers; Therapeutic; Prognostic 


\section{Introduction}

MicroRNAs play important roles in carcinogenesis and have significant impact on cancer research. Numerous microRNAs have been identified as potential cancer biomarkers and are involved as oncogenes, tumour suppressors as well as regulators of cancer stem cells. The discovery of microRNA targets and pathways has led to possible applications of microRNA-derived therapeutics in cancers including nasopharyngeal carcinoma (NPC). NPC is a neoplastic disorder that arises from the lining of the nasopharynx. It is commonly found in geographical areas such as Southern China and South-East Asia, with men: women prevalence ratio of 2-3 to 1 . Despite improvements in the management of patients with NPC over the years, it still remained as one of the most difficult malignancies to treat with 80,000 newly diagnosed cases every year and 50,000 annual deaths globally [1]. Its highly invasive nature is continuously being considered as a significant health problem in parts of the world where it is endemic. Hence, there is an urgent need to identify new diagnostic and potential therapeutic targets to help in the management of NPC.

\section{Roles of miRNA in NPC}

Over the years, many reports indicated that a high proportion of miRNAs are localised within fragile sites or cancer-associated regions, indicating that miRNAs play a significant role in the pathogenesis of cancer formation [2-6]. Indeed, many human miRNAs have been reported to alter biological activities such as cell proliferation and progression, apoptosis as well as metastasis in NPC and other cancers [6-9]. Several biological pathways that are crucial in carcinogenesis showed significant down-regulation of miRNAs [2, 4, 9, 10]. Despite this, most of these deregulated miRNAs are yet to be fully studied or understood [11]. 
Expression levels of miRNAs which were altered in nasopharyngeal carcinoma could potentially be involved in the pathogenesis of NPC by affecting the cell cycles at different levels by targeting different genetic pathways (Table 1).

\section{1 miRNAs as tumour suppressor genes}

Tumour suppressors function to inhibit cell proliferation, colony formation, migration and invasion in vitro, as well as tumour growth and metastasis in vivo [12-16]. miR-124 directly targeted Homo sapiens forkhead box Q1(Foxq1) and the level of miR-124 increased with clinical stage and T stage of patients with NPC [12]. In addition, miR-125a-5p increased the expression of $p 53$ and repressed the expression of human epidermal growth factor receptor 2 (Her2) (Figure 1), two important factors in apoptosis [13]. Similarly, miR31 induced apoptosis by targeting factor inhibiting HIF-1 (FIH1) and MCM2 genes (Figure 2). Inhibition of FIH1 was able to increase expression of p53 and p21. miR-31 also showed ability to attenuate in vitro anchorage-independent growth and in vivo tumourigenicity [16]. However, how miR-31 exercised its effect on them is still uncertain.

Similarly, miR-200a and miR-200b acted as tumour suppressors by inhibiting NPC cell growth, migration and invasion via down-regulation of zinc finger E-box binding homeobox 2 (ZEB2; also known as SIP1) and $\beta$-catenin (CTNNB1) and Notch1 respectively (Figure 3) [17, 18]. Two studies reported that miR-216b suppressed cell proliferation, invasion and metastasis by inhibiting the expression of protein kinase $\mathrm{C}$ alpha $(P K C \alpha)$ and Kirsten rat sarcoma viral oncogene homolog $(K R A S)$ protein $[19,20]$. On the other hand, overexpression of tumour suppressor miR-320a repressed NPC cell growth, migration, invasion and tumour growth in a xenograft mouse model by targeting BMI-1 [15] (Figure 3). In addition, ectopic expression of miR-451 was observed to suppress cell viability, colony formation, and cell migration and invasion by targeting macrophage migration inhibitory factor (MIF) gene (Figure 3) [21]. 


\section{$2.2 \quad$ miRNAs as oncogenes}

Oncogene miR-378 dramatically promoted cell proliferation, colony formation, migration and invasion in vitro, as well as tumour growth in vivo. When miR-378 was overexpressed, it was able to down-regulate the expression of transducer of HER2 (Figure 1) [22]. Likewise, tumour promoter miR-141 affected cell cycle, apoptosis, cell growth, migration and invasion in NPC cells by targeting bromodomain containing 3 (BRD3), ubiquitin associated protein 1 (UBAP1) and phosphatase and tensin homolog (PTEN) (Figure 1). $B R D 3$ is involved in the regulation of the $\mathrm{Rb} / \mathrm{E} 2 \mathrm{~F}$ pathway, a pathway which plays an important role in controlling cell growth leading to the induction of DNA replication and S phase in cell cycle [23] whilst PTEN is a crucial tumour suppressor in many tumour types [24, 25].

Studies revealed that miR-205 also repressed the expression of PTEN and upregulated the expression of protein kinase B (AKT) (Figure 1) [26]. miR-144 shared a similar target as it suppressed the expression of PTEN to increase the expression of $A K T$ and cyclin D1 (CCND1) proteins (Figure 2) to promote G1-phase transition and decreased cell apoptosis $[27,26]$. While miR-144 increased expression of CCND1 miR-138 directly targeted CCND1 (Figure 2). It was observed that overexpression of miR-138 lead to inhibition of cell growth and cell cycle progression in NPC cells [14].

In several scenarios, miRNAs that were able to inhibit certain target genes were in turn inhibited by the same gene targeted, showing a complex negative feedback mechanism. For example, miR-18b down-regulated connective tissue growth factor (CCN2 or CTGF) which subsequently lead to enhanced proliferation in vitro and in vivo via PI3K-AKT-C-Jun and C-Myc pathway (Figure 1). However, overexpression of CTGF in turn repressed the expression of miR-18b via PI3K-AKT-C-Jun and C-Myc pathway [21]. 


\subsection{Roles of miRNA in cell cycle progression}

Because any mutation towards cell cycle could possibly lead to uncontrolled proliferation, studies have also focused on miRNAs effect on cell cycle analysis. For example, miR-663 targeted p21WAF1/CIP1 to promote cellular G1/S transition leading to increased proliferation of NPC cells [28]. Similarly, by down-regulating multiple G1/S related cyclin/CDK/Rb/E2F signalling pathway, miR-188 was able to inhibit cell proliferation, tumour colony formation and G1/S cell cycle transition [29].

Tumour suppressor miR-26a inhibited cell proliferation and colony formation by inducing G1-phase cell-cycle arrest through repression of c-myc, cyclin D2, cyclin D3, cyclin E2, and cyclin-dependent kinase CDK4 and CDK6 expression whilst enhancing the expression of $C D K$ inhibitors such as $p 14 A R F$ and $p 21 C I P 1$ [30] (Figure 2). In another report, it was shown that miR-372 played a tumour suppressing role by inhibiting cell proliferation through down-regulation of CDK2 and cyclin A1 (CCNA1) as well as the upregulation of cyclin-dependent kinase inhibitor $1 \mathrm{~A}(C D K N 1 \mathrm{~A})$ and inhibitor of $\mathrm{CDK}$, cyclin A1 interacting protein 1 INCA1 [7]. miR-26a was also found to hamper migratory and invasive capacities of NPC cells in vitro and hindered metastatic behaviour of NPC cells in vivo possibly through the action of suppressing enhancer of zeste homolog 2 (EZH2) [31, 32]. A similar role was observed in miR-98 and miR-101 which attenuated EZH2 expression [32] (Figure 4). This study showed that it is possible for multiple miRNAs to influence a single gene target.

Although knowledge on specific roles of miRNAs in NPC are still lacking, evidences strongly suggest that miRNAs can either act as oncogenes (miR-93, miR-149 and miR-214) and/or tumour suppressors (miR-100, miR-143, miR-148a and Let-7) by regulating several biological processes including cell proliferation, migration, invasion and metastasis [33-39] (Table 2). In addition, the varsity of miRNAs, their multiple targets and their effects on 
various pathways show an extreme intricate web of connections in their ability to affect NPC progression (Figure 5).

\section{3. miRNA implicated in EBV positive NPC}

\subsection{Latent membrane protein 1}

Studies have shown that the aetiology of NPC is multifactorial, taking into account environmental factors, Epstein-Barr virus (EBV) infection, age and genetic background. However, it is unclear why certain individual with all the risk factors never develop NPC, whilst others who have no apparent risk factors do. Recently, an increasing amount of data has shown that EBV was able to regulate certain miRNAs which lead to NPC progression and invasion. EBV-encoded latent membrane protein one (LMP1) is one of the recognised oncogene that has been well studied and documented in the pathogenesis of NPC $[8,40]$. LMP1 simulates CD40 receptor and activate multiple cell signalling pathways such as inhibitor of differentiation, nuclear factor- $\kappa \mathrm{B}(N F-\kappa B)$, activator protein-1 (AP-1), signal transducers and activators of transcription (STAT), and tumour necrosis factor receptorassociated factors (TRAFs). Up-regulation of miR-146a by LMP1 suggested the possible oncogenic implication of miR-146a in the pathogenesis of NPC [41]. Additionally, increased LMP1 copies in NPC cell lines was correlated with an increase in miR-155 which stimulated NPC cell proliferation, colony formation, cell migration and invasion [42]. However, no studies were done on how miR-155 was able to exhibit its oncogene effect in NPC. Similarly, miR-10b was overexpressed in LMP1 expressing cell lines [33] and it in-turn up-regulated Ecadherin and enhanced the expression of matrix metallopeptidase 9 (MMP-9) (Figure 4) signifying the importance of miRNA in cancer invasion and metastasis [43].

Whilst some miRNAs stimulated NPC progression, others functioned as tumour suppressors. miR-203 was able to attenuate EBV-induced S-phase entry and transformation 
in vivo leading to suppression of NPC cell growth [44]. Also, mir-204 was able to inhibit EBV positive C666-1 cell invasion and metastasis partly through targeting cdc42 [45].

\subsection{BART miRNA}

Incredibly, EBV was able to produce its own miRNA called the BART miRNAs and BHRF1 miRNAs. They are encoded by two sets of transcripts, with one from the BART region and the other near the BHRF1 cluster. BART miRNAs and BHRF1 miRNAs were first identified as abundant viral transcripts generated from NPC in the early nineteen nineties [46, 47]. In usual miRNA biogenesis, one strand of the miRNA hairpins is selected to be the mature miRNA whilst the other strand is degraded [48]. However, both strands of the BART miRNA original hairpin can often persist and be functionally relevant [49]. To distinguish between these two potential miRNAs, the suffixes “-5p” and “-3p” have been used to designate the 5' end of the hairpin and 3' end of the hairpin [50]. Nowadays, BART gene accounts for 22 miRNA precursors which produces 44 mature BART miRNAs which are all suggested to be implicated in the pathogenesis of NPC [51].

The expression profile of EBV miRNAs has been comprehensively studied in NPC. Multiple reports confirmed the abundant expression of the BART miRNAs in NPC tissues in the absence of BHRF1 miRNAs. A recent study revealed that all 44 BART miRNAs were expressed in NPC tumours, at broadly similar levels [52]. Interestingly, approximately onesixth of the total miRNA content in NPC cells attributed to BART miRNAs, suggesting that BART miRNAs provided a considerable portion of the total regulatory influence of both viral and cellular genes in NPC tumour cells [53]. Edwards and colleagues established that the expression of these BART miRNAs was the highest in stage III but reduced in stage IV NPC samples, and were not noted in non-cancer biopsies and EBV-negative cell lines [54]. 
Several BART miRNAs have been subjected to further experiments and were shown to be implicated in the pathogenesis of NPC with their targets suggested or identified. Apoptosis was triggered by depleting miR-BART5 or inducing the expression of p53 upregulated modulator of apoptosis (PUMA) (Figure 6) in NPC cells [55], which is a proapoptotic member of the B-cell lymphoma $2(B C L-2)$ protein family [56]. PUMA is involved in p53 dependent and independent apoptosis induced by a variety of signals which after activation, interacts with anti-apoptotic $B C L-2$ family members $B A X$ and $B A K$ to signal apoptosis to the mitochondria. Following mitochondrial dysfunction, the caspase cascade is activated ultimately leading to cell death [57].

On the other hand, phosphoglycerate dehydrogenase $(P H G D H)$ expression levels were significantly up-regulated in the presence of high levels of miR-BART1 in NPC specimens. PHGDH diverted glucose-derived carbon into a specific biosynthetic pathway, contributing to carcinogenesis [58]. Another report showed that deleted in cancer 1 (DICE1), a tumour suppressor, was the cellular target of EBV miR-BART3 miRNA and expression of miR-BART3 overpowered the growth suppressive activity of DICE1 and stimulated cell proliferation [59].

Studies have reported that plasma miR-BART7 and miR-BART13 levels were significantly higher in patients with NPC when compared to healthy individuals. Their expressions enhanced proliferation, migration, and invasion of NPC cells and conferred tumour resistance to cisplatin $[60,61]$. The expression of miR-BART7 in NPC cells caused a large-scaled aberrant gene expressions, with genes related to the calcium signalling pathway being affected the most ( $\mathrm{p}=0.003$ ) [60]. It is worth noting that calcium signalling pathway has been implicated in the pathogenesis of several malignancies [62-64].

miR-BART9 was observed to target E-cadherin which enhanced migratory ability and invasiveness of NPC cells contributing to the aggressiveness of tumour cells [65]. It was also 
reported that miR-BART22 targeted mitogen-activated protein kinase kinase kinase 5 (MAP3K5) and LMP2A, inhibiting NPC cell apoptosis and, preventing their differentiation as well as permitting escape of EBV-infected cells from host immune surveillance [66, 67].

\section{Combining miRNA Treatment with Current NPC Treatments}

Long and colleagues showed that hypo-fractionated radiotherapy increased the expression of miR-34a, and stimulated p53 promoter activity and down-regulated the expression of c-Myc protein in NPC cells. When miR-34a was suppressed, hypo-fractionated radiotherapy seemed less effective in inhibiting NPC cell growth [68]. Their findings suggested that the effectiveness of current treatment of NPC may be a result of their modulation in miRNA expressions. Future therapy could place more emphasis in identifying potential miRNAs as molecular targeted therapy which could have fewer side effects in comparison with current NPC treatments. Undeniably, the combination of current chemotherapeutic drugs for NPC with miRNA has produced some promising results. miR-1 was shown to induce earlier apoptosis via targeting prothymosin alpha, ProTalpha (PTMA) when combined with chemotherapeutic agents such as actinomycin D, camptothecin and etoposide [69]. Similarly, miR-29c which showed anti-metastasis property by targeting $\mathrm{T}$ cell lymphoma invasion and metastasis 1 (TIAM1) gene [70] (Figure 4) was found to sensitise NPC cells to ionizing radiation and cisplatin treatment via inhibition of anti-apoptotic factors myeloid cell leukaemia $1(M C L-1)$ and $B C L-2$ (Figure 3), promoting apoptosis [31]. These evidences have opened up a new gateway of research to identify potential therapeutic targets for NPC. 


\section{5. miRNA as New Therapeutic Targets in NPC}

In view of the few strikingly altered differential miRNA expressions in NPC, the activation of tumour-suppressive miRNAs and/or inhibition of oncogenic miRNAs may have the potential to provide a fundamentally new approach for the development of therapeutics for NPC. Probably the most important advantage of miRNA gene therapy in comparison with current approaches of targeting single genes is its ability to modulate many different pathways or targets all at once, thus improving its effectiveness greatly [71]. Table 4 shows a summary on current evidences of miRNAs affected during radiotherapy. It is hoped that manipulating these miRNAs (miR-7, miR-23a, miR-29c, miR-205 and miR-451) could give similar anti-cancer effects towards NPC as radiotherapy but with less adverse side effects.

\section{6. miRNA as diagnostic and prognostic biomarker in NPC}

The main hindrance in combating NPC is the difficulty in early detection and accurate prognosis of the disease. This is partly a result of inadequate knowledge in the molecular pathogenesis of NPC. In addition, the lack of effective biomarkers and poor response to current therapies accounts for the large proportion of NPC patients ( $70 \%)$ being diagnosed at later stages [72-74]. An in-depth understanding of miRNA expression profiles might help identify potential reliable and robust biomarkers for early NPC detection. In the recent years, a number of miRNAs have been identified as potential diagnostic and prognostic markers in NPC (Table 3). Stable circulating miRNAs detected in plasma and serum present reliable and novel biomarkers for NPC diagnosis due to high sensitivity and medium specificity [89]. Liu and colleagues reported the diagnostic potentials $(\mathrm{p}<0.01)$ of five plasma miRNAs including miR-16, miR-21, miR-24 and miR -155. As a group, these miRNAs provided $87.7 \%$ of sensitivity and $82.0 \%$ of specificity for the diagnosis of NPC [90]. Hence, with enhanced 
knowledge and evidence about plasma miRNAs, it might facilitate the development of a noninvasive next-generation NPC screening approach.

\section{Conclusion}

Undoubtedly, the greatest challenge faced in application of miRNA biology in the clinical management of patients with NPC is the identification of the genes that each miRNA targets as reported in many cases.

Future miRNA investigation may focus on further elucidating the function of the miRNAs in this review. For example, miR-1 which shown positivity as an apoptotic miRNA can be tested on its efficiency as a therapeutic drug. On the other hand, a number of studies have been focusing on miR-29c. This tumour suppressor miRNA was targeted as a potential biomarker and studied for its anti-metastatic as well as pro-apoptotic effects towards NPC. However, studies on its effect towards laminin and collagen (often associated with solid tumour metastasis) have only been proven via bioinformatics studies. Future investigations may focus on identifying if miR-29c indeed target genes. In addition, it would also be interesting to find out the target gene(s) of miR-31 that reduces in vitro anchorageindependent growth and in vivo tumourigenicity of NPC.

Overall, further validations should be done on the miRNAs that are potentially useful for the diagnosis, prognosis or assessment of sensitivity to radiotherapy or chemotherapy in patients with nasopharyngeal carcinoma. New gene targeting therapies may be found when the targeting genes of the miRNAs are identified and studied. 


\section{Conflict of interest statements}

The authors have no conflict of interest in publishing this manuscript.

\section{Funding}

None

\section{Reviewers}

Suggested 


\section{References}

[1] Ferlay J, Shin HR, Bray F, Forman D, Mathers C, Parkin DM. Estimates of worldwide burden of cancer in 2008: GLOBOCAN 2008. Int J Cancer. 2010; 127:2893-917.

[2] Chen HC, Chen GH, Chen YH, Liao WL, Liu CY, Chang KP et al. MicroRNA deregulation and pathway alterations in nasopharyngeal carcinoma. Brit J Cancer. 2009; 100:1002-11.

[3] Schimanski CC, Frerichs K, Rahman F, Berger M, Lang H, Galle PR et al. High miR196a levels promote the oncogenic phenotype of colorectal cancer cells. World J Gastroenterol. 2009;15:2089-96.

[4] Gopalan V, Pillai S, Ebrahimi F, Salajegheh A, Lam TC, Le TK et al. Regulation of microRNA-1288 in colorectal cancer: altered expression and its clinicopathological significance. Mol Carcinog. 2014;53 Suppl 1:E36-44.

[5] Gopalan V, Smith RA, Lam AK. Downregulation of microRNA-498 in colorectal cancers and its cellular effects. Exp Cell Res. 2015;330:423-8.

[6] Amin M, Lam AK. Current perspectives of mi-RNA in oesophageal adenocarcinoma: Roles in predicting carcinogenesis, progression and values in clinical management. Exp Mol Pathol. 2015;98:411-8.

[7] Tan JK, Tan EL, Gan SY. Elucidating the roles of miR-372 in cell proliferation and apoptosis of nasopharyngeal carcinoma TW01 cells. Exp Oncol. 2014;36:170-3.

[8] Lee TW, Tan EL, Gan SY. The effect of cytokines on microRNA expression in TW01 nasopharyngeal carcinoma cells. Br J Med Med Res. 2013;3:11.

[9] Ebrahimi F, Gopalan V, Smith RA, Lam AK. miR-126 in human cancers: clinical roles and current perspectives. Exp Mol Pathol. 2014;96:98-107.

[10] 10 Ingersoll L, Woo SY, Donaldson S, Giesler J, Maor MH, Goffinet D et al. Nasopharyngeal carcinoma in the young: a combined M.D. Anderson and Stanford experience. Int J Radiat Oncol Biol Phys. 1990;19:881-7.

[11] Maroof H, Salajegheh A, Smith RA, Lam AK. Role of microRNA-34 family in cancer with particular reference to cancer angiogenesis. Exp Mol Pathol. 2014;97:298-304.

[12] Peng XH, Huang HR, Lu J, Liu X, Zhao FP, Zhang B et al. MiR-124 suppresses tumor growth and metastasis by targeting Foxq1 in nasopharyngeal carcinoma. Mol Cancer. 2014;13:186.

[13] Liu Y, Li Z, Wu L, Wang Z, Wang X, Yu Y et al. MiRNA-125a-5p: a regulator and predictor of gefitinib's effect on nasopharyngeal carcinoma. Cancer Cell Int. 2014;14:24.

[14] Liu X, Lv XB, Wang XP, Sang Y, Xu S, Hu K et al. MiR-138 suppressed nasopharyngeal carcinoma growth and tumorigenesis by targeting the CCND1 oncogene. Cell Cycle. 2012;11:2495-506.

[15] Qi X, Li J, Zhou C, Lv C, Tian M. MicroRNA-320a inhibits cell proliferation, migration and invasion by targeting BMI-1 in nasopharyngeal carcinoma. FEBS Lett. 2014;588:3732-8.

[16] Cheung CC, Chung GT, Lun SW, To KF, Choy KW, Lau KM et al. miR-31 is consistently inactivated in EBV-associated nasopharyngeal carcinoma and contributes to its tumorigenesis. Mol Cancer. 2014;13:1476-4598. 
[17] Xia H, Ng SS, Jiang S, Cheung WK, Sze J, Bian XW et al. miR-200a-mediated downregulation of ZEB2 and CTNNB1 differentially inhibits nasopharyngeal carcinoma cell growth, migration and invasion. Biochem Biophys Res Commun. 2010;391:535-41.

[18] Yang X, Ni W, Lei K. miR-200b suppresses cell growth, migration and invasion by targeting Notch1 in nasopharyngeal carcinoma. Cell Physiol Biochem. 2013;32:128898.

[19] Deng M, Liu JF, Gu YX, Zheng GP, He ZM. [miR-216b suppresses cell proliferation and invasion by targeting PKCalpha in nasopharyngeal carcinoma cells]. Zhonghua Zhong Liu Za Zhi. 2013;35:645-50.

[20] Deng M, Tang H, Zhou Y, Zhou M, Xiong W, Zheng Y et al. miR-216b suppresses tumor growth and invasion by targeting KRAS in nasopharyngeal carcinoma. J Cell Sci. 2011;124:2997-3005.

[21] Yu X, Zhen Y, Yang H, Wang H, Zhou Y, Wang E et al. Loss of connective tissue growth factor as an unfavorable prognosis factor activates miR-18b by PI3K/AKT/CJun and C-Myc and promotes cell growth in nasopharyngeal carcinoma. Cell Death Dis. 2013;4:e634.

[22] Yu BL, Peng XH, Zhao FP, Liu X, Lu J, Wang L et al. MicroRNA-378 functions as an onco-miR in nasopharyngeal carcinoma by repressing TOB2 expression. Int J Oncol. 2014;44:1215-22.

[23] Nevins JR. The Rb/E2F pathway and cancer. Hum Mol Genet. 2001;10:699-703.

[24] Chen P, Guo X, Zhou H, Zhang W, Zeng Z, Liao Q et al. SPLUNC1 regulates cell progression and apoptosis through the miR-141-PTEN/p27 pathway, but is hindered by LMP1. PLoS One. 2013;8:e56929.

[25] Zhang L, Deng T, Li X, Liu H, Zhou H, Ma J et al. microRNA-141 is involved in a nasopharyngeal carcinoma-related genes network. Carcinogenesis. 2010;31:559-66.

[26] Qu C, Liang Z, Huang J, Zhao R, Su C, Wang S et al. MiR-205 determines the radioresistance of human nasopharyngeal carcinoma by directly targeting PTEN. Cell cycle. 2012;11:785-96.

[27] Zhang LY, Ho-Fun Lee V, Wong AM, Kwong DL, Zhu YH, Dong SS et al. MicroRNA-144 promotes cell proliferation, migration and invasion in nasopharyngeal carcinoma through repression of PTEN. Carcinogenesis. 2013;34:454-63.

[28] Yi C, Wang Q, Wang L, Huang Y, Li L, Liu L et al. MiR-663, a microRNA targeting p21(WAF1/CIP1), promotes the proliferation and tumorigenesis of nasopharyngeal carcinoma. Oncogene. 2012;3:4421-33.

[29] Wu J, Lv Q, He J, Zhang H, Mei X, Cui K et al. MicroRNA-188 suppresses G 1 /S transition by targeting multiple cyclin/CDK complexes. Cell Commun Signal. 2014;12:66.

[30] Lu J, He ML, Wang L, Chen Y, Liu X, Dong Q et al. MiR-26a inhibits cell growth and tumorigenesis of nasopharyngeal carcinoma through repression of EZH2. Cancer Res. 2011;71:225-33.

[31] Yu L, Lu J, Zhang B, Liu X, Wang L, Li SY et al. miR-26a inhibits invasion and metastasis of nasopharyngeal cancer by targeting EZH2. Oncol Lett. 2013;5:1223-8.

[32] Alajez NM, Shi W, Hui AB, Bruce J, Lenarduzzi M, Ito E et al. Enhancer of Zeste homolog 2 (EZH2) is overexpressed in recurrent nasopharyngeal carcinoma and is regulated by miR-26a, miR-101, and miR-98. Cell Death Dis. 2010;1:e85. 
[33] Shi W, Alajez NM, Bastianutto C, Hui AB, Mocanu JD, Ito E et al. Significance of Plk1 regulation by miR-100 in human nasopharyngeal cancer. Int J Cancer. 2010;126:2036-48.

[34] Zhong W, He B, Zhu C, Xiao L, Zhou S, Peng X. [MiR-143 inhibits migration of human nasopharyngeal carcinoma cells by negatively regulating GLI3 gene]. Nan Fang Yi Ke Da Xue Xue Bao. 2013;33:1057-61.

[35] Li HP, Huang HY, Lai YR, Huang JX, Chang KP, Hsueh C et al. Silencing of miRNA-148a by hypermethylation activates the integrin-mediated signaling pathway in nasopharyngeal carcinoma. Oncotarget. 2014;5:7610-24.

[36] Wong TS, Man OY, Tsang CM, Tsao SW, Tsang RK, Chan JY et al. MicroRNA let-7 suppresses nasopharyngeal carcinoma cells proliferation through downregulating cMyc expression. J Cancer Res Clin Oncol. 2011;137:415-22.

[37] Lyu X, Fang W, Cai L, Zheng H, Ye Y, Zhang L et al. TGFbetaR2 is a major target of miR-93 in nasopharyngeal carcinoma aggressiveness. Mol Cancer. 2014;13:51.

[38] Luo Z, Zhang L, Li Z, Jiang C, Dai Y, Liu X et al. miR-149 promotes epithelialmesenchymal transition and invasion in nasopharyngeal carcinoma cells. Zhong Nan Da Xue Xue Bao Yi Xue Ban. 2011;36:604-9.

[39] Deng M, Ye Q, Qin Z, Zheng Y, He W, Tang H et al. miR-214 promotes tumorigenesis by targeting lactotransferrin in nasopharyngeal carcinoma. Tumour Biol. 2013;34:1793-800.

[40] Chew MM, Gan SY, Khoo AS, Tan EL. Interleukins, laminin and Epstein - Barr virus latent membrane protein 1 (EBV LMP1) promote metastatic phenotype in nasopharyngeal carcinoma. BMC Cancer. 2010;10:574.

[41] Zhao Y, Chen X, Jing M, Du H, Zeng Y. Expression of miRNA-146a in nasopharyngeal carcinoma is upregulated by Epstein-Barr virus latent membrane protein 1. Oncol Rep. 2012;28:1237-42.

[42] Zhu X, Wang Y, Sun Y, Zheng J, Zhu D. MiR-155 up-regulation by LMP1 DNA contributes to increased nasopharyngeal carcinoma cell proliferation and migration. Eur Arch Otorhinolaryngol. 2014;271:1939-45.

[43] Sun XJ, Liu H, Zhang P, Zhang XD, Jiang ZW, Jiang CC. miR-10b promotes migration and invasion in nasopharyngeal carcinoma cells. Asian Pac J Cancer Prev. 2013;14:5533-7.

[44] Yu H, Lu J, Zuo L, Yan Q, Yu Z, Li X et al. Epstein-Barr virus downregulates microRNA 203 through the oncoprotein latent membrane protein 1: a contribution to increased tumor incidence in epithelial cells. J Virol. 2012;86:3088-99.

[45] Ma L, Deng X, Wu M, Zhang G, Huang J. Down-regulation of miRNA-204 by LMP1 enhances CDC42 activity and facilitates invasion of EBV-associated nasopharyngeal carcinoma cells. FEBS Lett. 2014;588:1562-70.

[46] Gilligan KJ, Rajadurai P, Lin JC, Busson P, Abdel-Hamid M, Prasad U et al. Expression of the Epstein-Barr virus BamHI A fragment in nasopharyngeal carcinoma: evidence for a viral protein expressed in vivo. J Virol. 1991;65:6252-9.

[47] Al-Mozaini M, Bodelon G, Karstegl CE, Jin B, Al-Ahdal M, Farrell PJ. Epstein-Barr virus BART gene expression. J Gen Virol. 2009;90:307-16.

[48] Kim VN. MicroRNA biogenesis: coordinated cropping and dicing. Nat Rev Mol Cell Biol. 2005;6:376-85. 
[49] Kim do N, Lee SK. Biogenesis of Epstein-Barr virus microRNAs. Mol Cell Biochem. 2012;365:203-10.

[50] Marquitz AR, Raab-Traub N. The role of miRNAs and EBV BARTs in NPC. Semin Cancer Biol. 2012;22:166-72.

[51] Edwards RH, Marquitz AR, Raab-Traub N. Epstein-Barr virus BART microRNAs are produced from a large intron prior to splicing. Journal of virology. 2008;82:9094-106.

[52] Plieskatt JL, Rinaldi G, Feng Y, Levine PH, Easley S, Martinez E et al. Methods and matrices: approaches to identifying miRNAs for nasopharyngeal carcinoma. J Transl Med. 2014;12:3.

[53] Lo AK, Dawson CW, Jin DY, Lo KW. The pathological roles of BART miRNAs in nasopharyngeal carcinoma. J Pathol. 2012;227:392-403.

[54] Zeng Z, Huang H, Huang L, Sun M, Yan Q, Song Y et al. Regulation network and expression profiles of Epstein-Barr virus-encoded microRNAs and their potential target host genes in nasopharyngeal carcinomas. Sci China Life Sci. 2014;57:315-26.

[55] Choy EY, Siu KL, Kok KH, Lung RW, Tsang CM, To KF et al. An Epstein-Barr virus-encoded microRNA targets PUMA to promote host cell survival. J Exp Med. 2008;205:2551-60.

[56] Nakano K, Vousden KH. PUMA, a Novel Proapoptotic Gene, Is Induced by p53. Mol Cell.7:683-94.

[57] Yu J, Zhang L. PUMA, a potent killer with or without p53. Oncogene. 2008;27:S7183.

[58] Ye Y, Zhou Y, Zhang L, Chen Y, Lyu X, Cai L et al. EBV-miR-BART1 is involved in regulating metabolism-associated genes in nasopharyngeal carcinoma. Biochem Biophys Res Commun. 2013;436:19-24.

[59] Lei T, Yuen KS, Xu R, Tsao SW, Chen H, Li M et al. Targeting of DICE1 tumor suppressor by Epstein-Barr virus-encoded miR-BART3* microRNA in nasopharyngeal carcinoma. Int J Cancer. 2013;133:79-87.

[60] Chan JY, Gao W, Ho WK, Wei WI, Wong TS. Overexpression of Epstein-Barr virusencoded microRNA-BART7 in undifferentiated nasopharyngeal carcinoma. Anticancer Res. 2012;32:3201-10.

[61] Zhang G, Zong J, Lin S, Verhoeven RJ, Tong S, Chen Y et al. Circulating EpsteinBarr virus microRNAs miR-BART7 and miR-BART13 as biomarkers for nasopharyngeal carcinoma diagnosis and treatment. Int J Cancer. 2015;136:E301-12.

[62] Swami M. Signalling: the calcium connection. Nat Rev Cancer. 2010;10:738.

[63] Kim SY, Yang D, Myeong J, Ha K, Kim SH, Park EJ et al. Regulation of calcium influx and signaling pathway in cancer cells via TRPV6-Numb1 interaction. Cell calcium. 2013;53:102-11.

[64] Yang H, Zhang Q, He J, Lu W. Regulation of calcium signaling in lung cancer. J Thorac Dis. 2010;2:52-6.

[65] Hsu CY, Yi YH, Chang KP, Chang YS, Chen SJ, Chen HC. The Epstein-Barr virusencoded microRNA MiR-BART9 promotes tumor metastasis by targeting E-cadherin in nasopharyngeal carcinoma. PLoS Pathog. 2014;10:e1003974.

[66] Jiang QP, Liu SY, He XF, Peng J, Xiong HZ, Xiong ZT et al. [Relationship between MAP3K5 and Epstein-Barr virus-encoded miR-BART22 expression in nasopharyngeal carcinoma]. Nan Fang Yi Ke Da Xue Xue Bao. 2011;31:1146-9. 
[67] Lung RW, Tong JH, Sung YM, Leung PS, Ng DC, Chau SL et al. Modulation of LMP2A expression by a newly identified Epstein-Barr virus-encoded microRNA miR-BART22. Neoplasia. 2009;11:1174-84.

[68] Long Z, Wang B, Tao D, Huang Y, Tao Z. Hypofractionated radiotherapy induces miR-34a expression and enhances apoptosis in human nasopharyngeal carcinoma cells. Int J Mol Med. 2014;34:1388-94.

[69] Wu CD, Kuo YS, Wu HC, Lin CT. MicroRNA-1 induces apoptosis by targeting prothymosin alpha in nasopharyngeal carcinoma cells. J Biomed Sci. 2011;18:80.

[70] Liu N, Tang LL, Sun Y, Cui RX, Wang HY, Huang BJ et al. MiR-29c suppresses invasion and metastasis by targeting TIAM1 in nasopharyngeal carcinoma. Cancer Lett. 2013;329:181-8.

[71] Vosgha H, Salajegheh A, Smith RA, Lam AK. The important roles of miR-205 in normal physiology, cancers and as a potential therapeutic target. Curr Cancer Drug Targets. 2014;14:621-37.

[72] Arango BA, Castrellon AB, Perez CA, Raez LE, Santos ES. Nasopharyngeal carcinoma: alternative treatment options after disease progression. Expert Rev Anticancer Ther. 2010;10:377-86.

[73] Sheng L, Shui Y, Shen L, Wei Q. Effect of patient-related delay in diagnosis on the extent of disease and prognosis in nasopharyngeal carcinoma. Am J Rhinol. 2008;22:317-20.

[74] Wei WI, Sham JS. Nasopharyngeal carcinoma. Lancet. 2005;365:2041-54.

[75] Li T, Chen JX, Fu XP, Yang S, Zhang Z, Chen Kh H et al. microRNA expression profiling of nasopharyngeal carcinoma. Oncol Rep. 2011;25:1353-63.

[76] Sengupta S, den Boon JA, Chen IH, Newton MA, Stanhope SA, Cheng YJ et al. MicroRNA 29c is down-regulated in nasopharyngeal carcinomas, up-regulating mRNAs encoding extracellular matrix proteins. Proc Natl Acad Sci U S A. 2008;105:5874-8.

[77] Lu J, Xu X, Liu X, Peng Y, Zhang B, Wang L et al. Predictive value of miR-9 as a potential biomarker for nasopharyngeal carcinoma metastasis. Br J Cancer. 2014;110:392-8.

[78] Zeng X, Xiang J, Wu M, Xiong W, Tang H, Deng M et al. Circulating miR-17, miR20a, miR-29c, and miR-223 combined as non-invasive biomarkers in nasopharyngeal carcinoma. PLoS One. 2012;7:e46367.

[79] Liu Y, Cai H, Liu J, Fan H, Wang Z, Wang Q et al. A miR-151 binding site polymorphism in the 3'-untranslated region of the cyclin E1 gene associated with nasopharyngeal carcinoma. Biochem Biophys Res Commun. 2013;432:660-5.

[80] Du ZM, Hu LF, Wang HY, Yan LX, Zeng YX, Shao JY et al. Upregulation of MiR155 in nasopharyngeal carcinoma is partly driven by LMP1 and LMP2A and downregulates a negative prognostic marker JMJD1A. PLoS One. 2011;6:e19137.

[81] Li G, Liu Y, Su Z, Ren S, Zhu G, Tian Y et al. MicroRNA-324-3p regulates nasopharyngeal carcinoma radioresistance by directly targeting WNT2B. European journal of cancer (Oxford, England : 1990). 2013;49:2596-607.

[82] Liu N, Jiang N, Guo R, Jiang W, He QM, Xu YF et al. MiR-451 inhibits cell growth and invasion by targeting MIF and is associated with survival in nasopharyngeal carcinoma. Mol Cancer. 2013;12:123. 
[83] Zheng XH, Cui C, Ruan HL, Xue WQ, Zhang SD, Hu YZ et al. Plasma microRNA profiling in nasopharyngeal carcinoma patients reveals miR-548q and miR-483-5p as potential biomarkers. Chin J Cancer. 2014;33:330-38.

[84] Chen ZX, Sun AM, Chen Y, Liu Y, Zhan JF, Chen LH et al. [Effects of radiosensitivity and $\mathrm{X}$-ray dose on miR-7 expression in nasopharyngeal carcinoma]. Nan Fang Yi Ke Da Xue Xue Bao. 2010;30:1810-16.

[85] Li XH, Qu JQ, Yi H, Zhang PF, Yi HM, Wan XX et al. Integrated analysis of differential miRNA and mRNA expression profiles in human radioresistant and radiosensitive nasopharyngeal carcinoma cells. PLoS One. 2014;9:e87767.

[86] Zhang JX, Qian D, Wang FW, Liao DZ, Wei JH, Tong ZT et al. MicroRNA-29c enhances the sensitivities of human nasopharyngeal carcinoma to cisplatin-based chemotherapy and radiotherapy. Cancer Lett. 2013;329:91-98.

[87] Wang D, Wang S, Liu Q, Wang M, Wang C, Yang H. SZ-685C exhibits potent anticancer activity in both radiosensitive and radioresistant NPC cells through the miR-205-PTEN-Akt pathway. Oncol Rep. 2013;29:2341-47.

[88] Zhang T, Sun Q, Liu T, Chen J, Du S, Ren C et al. MiR-451 increases radiosensitivity of nasopharyngeal carcinoma cells by targeting ras-related protein 14 (RAB14). Tumour Biol. 2014;35:12593-99.

[89] Zhiyi Wang, Wei Chen, Yong Zhang, Li Xu, Qiuping Wang. Diagnostic value of circulating microRNAs for nasopharyngeal cancer: A systematic review and metaanalysis. J Cancer Res Ther. 2014;10:173-78.

[90] Xiong Liu, Hua-Nan Luo, Wen-Dong Tian, Juan Lu, Gang Li, Lu Wang et al. Diagnostic and prognostic value of plasma microRNA deregulation in nasopharyngeal carcinoma. Cancer Biol Ther. 2013;14:1133-42. 


\section{Biographies}

Prof. Alfred K.Y. Lam is an internationally recognized authority in diagnostic and molecular pathology of endocrine cancer with 25 years of activity this field. He has published more than 280 articles in peer reviewed journals and has written book chapters in World Health Organization's classification of tumours. His publications have attracted high citations in the research field with the citation index (Scopus H-index) for his publications at 44 for 2016. He also serves on editorial boards for a few international peer reviewed journals.

Dr. Sook-Yee Gan is the Head of the Life Sciences department at the School of Pharmacy, International Medical University in Malaysia. She has a leading role in the development and implementation of the IMU Master of Science in Molecular Medicine Programme. Her research interests include miRNA research in cancers (particularly nasopharyngeal carcinoma) and gene expression profiling. In addition, she is also involved in other studies including genetic engineering of algae and exploring the potential application of algae in the treatment of neurodegenerative disorders.

Miss. Katherine Ting-Wei Lee has eight years of experience in cancer research from drug discovery to studying the molecular aspects of cancer. One of her previous research was focused on miRNA and gene expression profiling in nasopharyngeal carcinoma. She is currently a PhD candidate currently investigating the molecular role of GAEC1 in colorectal cancer pathogenesis to further understand the role of this novel gene in colorectal cancer.

Dr. Juan-King Tan initially underwent his medical training at the International Medical University in Malaysia where he also spent a year intercalating a Bachelor of Medical Sciences prior to transferring to the University of Warwick in the UK to complete his clinical training. During his intercalation year he discovered great interests for research for which he remained an active researcher in the field of cancer cell molecular biology following his graduation. Tan is currently a Foundation House Officer at Aberdeen Royal Infirmary. 


\section{Table}

Table 1: Aberrantly expressed human miRNAs in nasopharyngeal carcinoma

\begin{tabular}{lll}
\hline Regulation & $\begin{array}{l}\text { Number } \\
\text { of } \\
\text { Studies }\end{array}$ & miRNAs \\
\hline 2 & miR-15b [2, 52], miR-18a [2, 75], miR-205 [2, 52], miR-25 [2, 52] \\
\hline Up & miR-106a [2], miR-1268a [52], miR1268b [52], miR-1303 [52], \\
& miR-1304 [52], miR-1305 [52], miR-138 [2], miR-142-3p [2], \\
& miR-151 [76], miR-155 [2], miR-17 [2], miR-184 [52], miR-192 \\
& [76], miR-196b [2], miR-21 [52], miR-27a [52], miR-378 [22], \\
& miR-4677 [52], miR-4791 [52], miR548n [52], miR-6510 [52], \\
& miR-92a [52], miR-944 [52] \\
& miR-34b [76, 2, 75], miR-100 [2, 52, 75], miR-152 [2, 52, 75], \\
& miR-195 [2, 52, 75], miR-497 [2, 52, 75] \\
& let-7b [52, 75], let-7f [52, 75], miR-10b [52, 75], miR-29c [76, 2], \\
& miR-34c [76, 75], miR-130a [2, 52], miR-143 [2, 52], miR-145 [2, \\
& 52], miR-148a [2, 52] \\
& HS_204.1 [75], HS_210 [75], HS_38.1 [75], let-7a [75], let-7c \\
& [75], let-7d [75], let-7e [75], let-7g [75], miR-10a [52], miR-1251 \\
& [52], miR-126 [52], miR-1269 [52], miR-133a [52], miR-133b \\
& [52], miR-135a [2], miR-136 [52], miR-139 [52], miR-139-5p [2], \\
& miR-150 [75], miR-151a [52], miR-155 [75], miR-182 [52], miR- \\
& 187 [2], miR-199a [52], miR-199b-5p [2], miR-200a [2], miR- \\
& 200b [2], miR-204 [2, 52], miR-21 [52], miR-212 [76], miR-214 \\
& [52], miR-216 [76], miR-217 [76], miR-221 [75], miR-26a [52], \\
& miR-26b [75], miR-27b [52], miR-29a [75], miR-29b [75], miR- \\
& 300 [52], miR-3065 [52], miR-30a [2], miR-30d [75], miR-31 [2], \\
& miR-335 [52], miR-342 [75], miR-34c-3p [2], miR-34c-5p [2], \\
& miR-375 [75], miR-376a [52], miR-376c [52], miR-376b-5p [52], \\
& miR-425-5p [75], miR-4423 [52], miR-449 [75], miR-449a [2], \\
& miR-450a [52], miR-4792 [52], miR-488 [52], miR-504 [52], miR- \\
& 532-3p [2], miR-542 [52], miR-556 [52], miR-574 [52], miR-576 \\
& [75], miR-584 [52], miR-585 [52], miR-625 [75], miR-642 [75], \\
& miR-768-3p [75], miR-874 [52], miR-887 [52], miR-891a [52], \\
& miR-9 [2], miR-92b [75] \\
& \\
& & \\
& & \\
& &
\end{tabular}


Table 2: Example of miRNAs as tumour suppressors or oncogenes in nasopharyngeal carcinoma (NPC)

\begin{tabular}{|c|c|c|c|}
\hline $\begin{array}{l}\text { Tumour } \\
\text { Suppressor/ } \\
\text { Oncogene }\end{array}$ & Author/Year & miRNA & Remarks \\
\hline \multirow[t]{4}{*}{$\begin{array}{l}\text { Tumour } \\
\text { suppressor }\end{array}$} & Shi/2010 [33] & miR-100 & $\begin{array}{l}\text { Decreased miR-100 was associated with an } \\
\text { increased in PIK1 contributing to NPC } \\
\text { progression }\end{array}$ \\
\hline & Zhong/ [34] & miR-143 & $\begin{array}{l}\text { Regulate invasiveness and metastasis of NPC. } \\
\text { Overexpression of miR- } 143 \text { causes a significant } \\
\text { reduction of the adhesion ability by targeting } \\
\text { GLI3 }\end{array}$ \\
\hline & Li/2013 [35] & miR-148a & $\begin{array}{l}\text { Inhibit cell migration in NPC cells by targeting } \\
V A V 2, W A S L \text { and } R O C K 1\end{array}$ \\
\hline & $\begin{array}{l}\text { Wong/2011 } \\
{[36]}\end{array}$ & Let-7 & $\begin{array}{l}\text { Inhibit NPC cell proliferation by repressing c- } \\
\text { myc }\end{array}$ \\
\hline \multirow[t]{3}{*}{ Oncogene } & Lyu/2014 [37] & miR-93 & $\begin{array}{l}\text { Down-regulate transforming growth factor- } \beta \\
\text { receptor II (TGF } \beta R 2 \text { ) and causing attenuation of } \\
\text { Smad-dependent TGF- } \beta \text { signalling and the } \\
\text { activation of PI3K/Akt pathway which led to } \\
\text { cell proliferation, invasion and metastasis of } \\
\text { NPC }\end{array}$ \\
\hline & Luo/2011 [38] & miR-149 & $\begin{array}{l}\text { Promote proliferation of NPC cell lines by } \\
\text { increasing E-cadherin }\end{array}$ \\
\hline & $\begin{array}{l}\text { Deng/2013 } \\
\text { [39] }\end{array}$ & miR-214 & $\begin{array}{l}\text { Mimics significantly repressed lactotransferrin } \\
(L T F) \text { mRNA and protein levels in NPC cells to } \\
\text { promote NPC cell proliferation and invasion in } \\
\text { addition to hastening tumour formation and } \\
\text { lung metastasis in mouse xenografts. }\end{array}$ \\
\hline
\end{tabular}


Table 3: Potential diagnostic and prognostic miRNAs in nasopharyngeal carcinoma

\begin{tabular}{|c|c|c|}
\hline Article/year & miRNA & Remarks \\
\hline $\begin{array}{l}\mathrm{Lu} / 2014 \\
{[77]}\end{array}$ & miR-9 & $\begin{array}{l}\text { Significantly decreased level of miR-9 in patients with NPC } \\
\text { was confirmed through two-stage validation. Low level of } \\
\text { plasma miR-9 was significantly correlated with lymphatic } \\
\text { invasion and advanced TNM stage. The plasma miR-9 level } \\
\text { was significantly elevated in post-treatment plasma } \\
\text { compared with those pre-treatment samples. }\end{array}$ \\
\hline $\begin{array}{l}\text { Zeng/2012 } \\
{[78]}\end{array}$ & $\begin{array}{l}\operatorname{miR}-17 \\
\operatorname{miR}-20 a \\
\text { miR-29c } \\
\text { miR-223 }\end{array}$ & $\begin{array}{l}\text { Microarray-based serum miRNA profiling on the serum of } \\
\text { twenty nasopharyngeal carcinoma patients at diagnosis } \\
\text { along with } 20 \text { non-cancerous individuals as controls was } \\
\text { carried out in which miR-17, miR-20a, miR-29c, and miR- } \\
223 \text { were found to be expressed differentially in the serum of } \\
\text { patients with NPC compared with those of non-cancerous } \\
\text { control. }\end{array}$ \\
\hline $\begin{array}{l}\text { Liu Y/2014 } \\
{[13]}\end{array}$ & miR-125a-5p & $\begin{array}{l}\text { Functioned as a regulator and predictor of effect of } \\
\text { gefitinib's on NPC }\end{array}$ \\
\hline $\begin{array}{l}\text { Liu Y/2013 } \\
{[79]}\end{array}$ & miR-151 & $\begin{array}{l}\text { CCNE1's polymorphisms located at miRNA-151 binding } \\
\text { sites are associated with NPC susceptibility and are } \\
\text { correlated with pathological stages of NPC. }\end{array}$ \\
\hline $\begin{array}{l}\mathrm{Du} / 2011 \\
{[80]}\end{array}$ & miR-155 & $\begin{array}{l}\text { Driven by } L M P 1 \text { and } L M P 2 A \text { and down-regulated JMJD1A. } \\
\text { Down-regulation of JMJDA was significantly correlated } \\
\text { with advanced N stage, a lower five-year survival rare and a } \\
\text { lower five-year disease-free survival rate in patients with } \\
\text { NPC. }\end{array}$ \\
\hline $\begin{array}{l}\mathrm{Ma} / 2014 \\
{[45]}\end{array}$ & miR-204 & $\begin{array}{l}\text { Low-level expression of miR-204 was significantly } \\
\text { associated with a more aggressive and poor prognostic } \\
\text { phenotype of NPC. }\end{array}$ \\
\hline $\begin{array}{l}\text { Deng/2013 } \\
{[19]}\end{array}$ & miR-216b & $\begin{array}{l}\text { Decreased expression of miR-216b was directly related to } \\
\text { advanced clinical stage and lymph node metastasis whilst } \\
\text { miR-216b levels correlated inversely with levels of KRAS } \\
\text { protein during nasopharyngeal carcinogenesis }\end{array}$ \\
\hline Li/2013 [81] & $\begin{array}{l}\text { miRNA-324- } \\
3 p\end{array}$ & $\begin{array}{l}\text { Down-regulation of miRNA-324-3p and up-regulation of } \\
\text { WNT } 2 B \text { were significantly correlated with advanced clinical } \\
\text { stages of NPC }\end{array}$ \\
\hline $\begin{array}{l}\mathrm{Liu} / 2013 \\
{[82]}\end{array}$ & miR-451 & $\begin{array}{l}\text { miR- } 451 \text { was significantly down-regulated in NPC cell lines } \\
\text { and clinical tissues }(\mathrm{P}<0.01) \text { and patients with low } \\
\text { expression of miR- } 451 \text { had poorer overall survival and } \\
\text { disease-free survival. }\end{array}$ \\
\hline $\begin{array}{l}\text { Zheng/2014 } \\
\text { [83] }\end{array}$ & $\begin{array}{l}\text { miR-483-5p } \\
\text { miR-548q }\end{array}$ & $\begin{array}{l}\text { Most patients with NPC with poor outcome exhibited high } \\
\text { expression of miR-548q (70.6\%) and miR-483-5p (64.7\%) } \\
\text { in tissue samples, indicating their prognostic value. }\end{array}$ \\
\hline
\end{tabular}


Table 4: Possible miRNAs as future therapeutic targets in NPC

\begin{tabular}{|c|c|c|}
\hline Author/Year & miRNA & Remarks \\
\hline $\begin{array}{l}\text { Chen/2010 } \\
{[84]}\end{array}$ & miR-7 & $\begin{array}{l}\text { Radio-sensitivity and radiation dose of X-ray have significant } \\
\text { effect on the expression of miR-7 in NPC cells, indicating that } \\
\text { miR-7 plays an important role in radio-resistance of NPC cells to } \\
\text { X-ray. Suppression of miR-7 expression may elevate the radio- } \\
\text { sensitivity of NPC cells. }\end{array}$ \\
\hline Li/2014 [85] & miR-23a & $\begin{array}{l}\text { miRNA-23a was involved in radio-resistance of NPC through } \\
\text { directly targeting IL-8. }\end{array}$ \\
\hline $\begin{array}{l}\text { Zhang/2013 } \\
{[86]}\end{array}$ & miR-29c & $\begin{array}{l}\text { Low expression of miR-29c was positively associated with } \\
\text { therapeutic resistance in NPC. Further in vitro and in vivo studies } \\
\text { illustrated ectopic restoration of miR-29c substantially enhanced } \\
\text { the sensitivity of NPC cells to ionising radiation and cisplatin } \\
\text { treatment by promoting apoptosis, and also repressed expression } \\
\text { of anti-apoptotic factors Mcl-1 and Bcl-2 in NPC tissues and cell } \\
\text { lines. }\end{array}$ \\
\hline $\begin{array}{l}\text { Wang/2013 } \\
\text { [87] }\end{array}$ & miR-205 & $\begin{array}{l}\text { Anthracycline analogue isolated from the secondary metabolites } \\
\text { of the mangrove endophytic fungus no. } 1403 \text { collected from the } \\
\text { South China Sea (SZ-685C) exhibited pro-apoptotic activity in } \\
\text { both radiosensitive and radio-resistant NPC cells and was shown } \\
\text { to abrogate the radio-resistance of NPC cells through the miR- } \\
\text { 205-PTEN-Akt pathway. }\end{array}$ \\
\hline $\begin{array}{l}\text { Zhang/2014 } \\
{[88]}\end{array}$ & miR-451 & $\begin{array}{l}\text { High levels of miR- } 451 \text { expression enhanced radio-sensitivity in } \\
\text { NPC cells by inhibiting the repair of irradiation-induced double- } \\
\text { strand breaks and increasing apoptosis by down-regulation of } \\
R A B 14 \text {. }\end{array}$ \\
\hline
\end{tabular}




\section{Figures Legends}

Figure 1: miRNAs involved in NPC cell apoptosis through Smad-dependent TGF- $\beta$ signalling pathway, PI3K-Akt signalling pathway and EBV infection pathway. Green colour indicates tumour suppressor miRNAs, orange colour indicates oncogene miRNAs, yellow colour indicates gene in the pathways, solid arrow $(\longrightarrow)$ indicates direct target, dashline arrow $(-\rightarrow)$ ) indicates downstream target, blunt ended lines $(-\rightarrow)$ indicates direct inhibition of target gene and blunt ended dash lines $(-\dashv)$ indicates downstream inhibition target gene.

Figure 2: miRNAs involved in NPC cell G1/S cell cycle arrest or cell cycle progression. Green colour indicates tumour suppressor miRNAs, orange colour indicates oncogene miRNAs, yellow colour indicates gene in the pathways, solid arrow $(\longrightarrow)$ indicates direct target, dash-line arrow $(-\rightarrow$ ) indicates downstream target, blunt ended lines $(-\rightarrow)$ indicates direct inhibition of target gene and blunt ended dash lines ( ---1$)$ indicates downstream inhibition target gene.

Figure 3: Tumour suppressor miRNAs involved in attenuating NPC cell growth, migration, invasion or metastasis through affecting PI3K-Akt signalling pathway and Wnt signalling pathway.

Green colour indicates tumour suppressor miRNAs, yellow colour indicates gene in the pathways, solid arrow ( $\longrightarrow$ ) indicates direct target, dash-line arrow $(--\rightarrow$ ) indicates downstream target and blunt ended lines $(-\rightarrow)$ indicates direct inhibition of target gene.

Figure 4: miRNAs involved in NPC cell migration, invasion or metastasis through ECM-receptor interaction, Hedgehog Signaling pathway and Wnt signaling pathway. Green colour indicates tumour suppressor miRNAs, orange colour indicates oncogene miRNAs, yellow colour indicates gene in the pathways, solid arrow $(\longrightarrow)$ indicates direct target, dash-line arrow $(-\rightarrow$ ) indicates downstream target and blunt ended lines $(\rightarrow)$ indicates direct inhibition of target gene.

Figure 5: Overall miRNAs involved in NPC.

Green colour indicates tumour suppressor miRNAs, orange colour indicates oncogene miRNAs, yellow colour indicates gene in the pathways, solid arrow $(\longrightarrow$ ) indicates direct target, dash-line arrow $(-\rightarrow$ ) indicates downstream target, blunt ended lines $(-1)$ indicates direct inhibition of target gene and blunt ended dash lines $(-\rightarrow)$ indicates downstream inhibition target gene.

Figure 6: BART-miRNAs involved in NPC cell proliferation, apoptosis, migration, invasion and tumour resistance against chemo-radiotherapy either through direct, glycolytic, or MAPK-signalling pathway.

Orange colour indicates oncogene miRNAs, yellow colour indicates gene in the pathways, solid line $(-)$ indicates association, solid arrow $(\longrightarrow)$ indicates direct target, dash-line arrow $(-\rightarrow)$ indicates downstream target and blunt ended lines $(-\rightarrow)$ indicates direct inhibition of target gene. 